\title{
ANTRO TIPO MIOKARDO INFARKTAS
}

\author{
Pranas Šerpytis ${ }^{1}$, Sigita Glaveckaitè ${ }^{1}$, Eglẻ Butkute் ${ }^{2}$, Agnẻ Jucevičienė ${ }^{1}$, Rokas Šerpytis ${ }^{1}$ \\ ${ }^{I}$ Vilniaus universiteto ligonine Santaros klinikos, ${ }^{2}$ Vilniaus universiteto Medicinos fakultetas
}

Raktažodžiai: antro tipo miokardo infarktas, miokardo infarktas, miokardo infarkto klasifikacija

\section{Santrauka \\ Miokardo infarktas - pagrindinè mirties priežastis daugelyje pasaulio šalių. I klinikinę praktiką ịvedus laboratorinị troponinų tyrimą, pagerèjo miokardo iš- emijos, įvykusios ne dèl vainikinių kraujagyslių ste- nozės, diagnostika. 2007 m. universalaus miokardo infarkto apibrèžimo tarptautinio susitarimo doku- mente buvo išskirti 5 miokardo infarkto tipai. I ir II tipo išskyrimas sukèlè nemažai painiavos, trūksta duomenų apie I ir II miokardo infarkto tipų dažnio,} simptomatikos ir baigčių skirtumus.

Tyrimo tikslas - ivertinti miokardo infarkto eigos, pasireiškimo, gydymo ir baigčių skirtumus pacientams, sergantiems I ir II tipų miokardo infarktu.

Tyrimo metodika - atliktas retrospektyvinis tyrimas. I tyrimą įtraukti 1583 tiriamieji, kurie dèl I arba II tipo miokardo infarkto 2011 - 2015 metais buvo hospitalizuoti Vilniaus universiteto ligonineje Santaros klinikose ir įtraukti ị ūmių koronarinių sindromų duomenų bazę. Lyginti pacientų su I ir II tipo miokardo infarktu demografiniai duomenys, laboratoriniai rodikliai, intervencinis ir medikamentinis gydymas, ligos baigtys. Tyrimo rezultatai - I tipo miokardo infarktas buvo diagnozuotas 1467 pacientams (87,95\%), II tipo 116 pacientu $(6,95 \%)$. Pacientams, sergantiems II tipo miokardo infarktu, dažniau diagnozuota anemija, tachikardija, dažnesnis naujai atsiradęs prieširdžių virpejjimas, dažniau nustatomas reikšmingai sumažèjęs funkcinis pajègumas, stebèta mažesnè troponino koncentracija, rečiau diagnozuojamas kelių vainikinių arterijų pažeidimas. Šiems pacientams rečiau skirtas gydymas antiagregantais. Be to, mirštamumas ligoninejje didesnis tarp pacientų, sergančių II tipo miokardo infarktu.

Išvados - II tipo miokardo infarktas diagnozuotas beveik 12 kartų rečiau negu I tipo. Pacientams, sergantiems II tipo miokardo infarktu, nustatyta mažesnè troponino koncentracija, šiems pacientams rečiau taikytas gydymas antiagregantais ir intervencinis gydymas, stebètas mažesnis funkcinis pajègumas ir didesnis hospitalinis mirštamumas.

\section{Ivvadas}

Miokardo infarktas (toliau - MI) - pagrindinè mirties priežastis daugelyje pasaulio šalių. Sveikatos priežiūros specialistų tikslas - laiku diagnozuoti MI ir skirti tinkamą gydymą, skubiai atstatyti miokardo kraujotaką ir sumažinti pažeisto širdies raumens apimtị [1]. Didelị postūmį ūmių koronarinių sindromų diagnostikoje turejo ,auksinį standartą " - kreatinkinazès MB izofermentą pakeitusių troponino I ir troponino T, vèliau ir didelio jautrumo troponino, atsiradimas. Greitai buvo pastebėta, kad troponinų padidejjimą sukelia ir ivairios kitos ligos, pvz., inkstų funkcijos nepakankamumas. Be to, identifikuotos naujos būklès - Tako-tsubo kardiomiopatija ir spontaniné vainikinių arterijų disekacija, pamėgdžiojančios MI [2].

Siekiant spręsti troponino padidejjimo ne tik tradicinio MI metu problemą, 2007 metais publikuotame universalaus

1 lentelè. Miokardo infarkto klasifikacija

$M I$ - miokardo infarktas, KHPKB - kairès Hiso pluošto kojytès blokada.

\begin{tabular}{|l|l|}
\hline Tipas & \multicolumn{1}{c|}{ Apibrèžimas } \\
\hline I & $\begin{array}{l}\text { MI dėl išemijos sukelto pirminio koronarinio įvykio - } \\
\text { plokštelès erozijos, plyšimo, išopėjimo. }\end{array}$ \\
\hline II & $\begin{array}{l}\text { MI dėl išemijos sukeltos sumažėjusio deguonies ap- } \\
\text { rūpinimo arba padidėjusio poreikio (pvz., vainikinės } \\
\text { arterijos spazmas, vainikinės arterijos embolija, ane- } \\
\text { mija, aritmijos, hipertenzija ar hipotenzija). }\end{array}$ \\
\hline III & $\begin{array}{l}\text { Staigi, netikèta mirtis dèl širdies veiklos sutrikimo, } \\
\text { įskaitant širdies sustojimą su miokardo išemijos simp- } \\
\text { tomais kartu su nauju ST segmento pakilimu, ar naujai } \\
\text { atsiradusia KHPKB, ar trombo vainikinėse arterijose } \\
\text { ịrodymu angiografijos ir/ar autopsijos metu, kai mirtis } \\
\text { ịvyko prieš paimant kraujo mėginius ar prieš širdies } \\
\text { žymenų padidejjimą kraujyje. }\end{array}$ \\
\hline IV & $\begin{array}{l}\text { MI išsivystęs dėl stento trombozės, remiantis angio- } \\
\text { grafijos arba autopsijos duomenimis. }\end{array}$ \\
\hline V & MI susijęs su aortokoronarinių jungčių operacija. \\
\hline
\end{tabular}

Adresas susirašinėti: Eglè Butkute, el. p. ebutkute@gmail.com 
miokardo infarkto apibrěžimo tarptautinio susitarimo dokumente buvo išskirti 5 MI tipai (1 lentelè) [3-5]. Šis dokumentas - tai $2000 \mathrm{~m}$. publikuoto originalaus dokumento atnaujinimas [6]. Tolimesniame, $2012 \mathrm{~m}$. išleistame dokumento atnaujinime MI klasifikacija ị 5 tipus taip pat išlieka [7].

I tipo MI, dar vadinamas tradiciniu MI, ịvyksta dèl vainikinių arterijų obstukcijos, išsivysčiusios išopejjus, plyšus ar kitaip pakitus aterosklerozinei plokštelei. Pacientams su II tipo MI stebimas miokardo deguonies poreikio ir aprūpinimo krauju disbalansas. Skirtingų MI etiologijų išskyrimas svarbus pasirenkant gydymo taktiką. I tipo MI atveju būtinas skubus kraujagyslès atvėrimas, o pacientams su II tipo MI reikalingas išemiją sukèlusių priežasčių gydymas. II tipo MI išskyrimas įnešè nemažai diskusijų ir painiavos. Sunkumų sukẻlè aiškių kriterijų, padedančių atskirti I tipo MI nuo II tipo MI nebuvimas [6]. Taip pat trūksta duomenų apie I ir II MI tipo dažnio, simptomatikos ir baigčių skirtumus.

Tyrimo tikslas - ịvertinti MI eigos, pasireiškimo, gydymo ir baigčių skirtumus pacientams, sergantiems I ir II tipo MI.

\section{Tyrimo metodika}

Atliktas retrospektyvinis tyrimas. I tyrimą įtraukti 1583 tiriamieji, kurie dèl I arba II tipo MI 2011 - 2015 metais buvo hospitalizuoti Vilniaus universiteto ligonineje Santaros klinikose ir ịtraukti ị ūmių koronarinių sindromų duomenų bazę. Lyginti pacientų su I ir II tipo MI demografiniai duomenys: amžius, lytis; klinikiniai parametrai: anemija, tachikardija, naujai atsiradęs prieširdžių virpèjimas, funkcinis pajègumas; laboratoriniai rodikliai: troponinas, kreatininas, smegenu natriuretinio peptido (BNP) koncentracija, koronarografijos data, intervencinis ir medikamentinis gydymas, ligos baigtys.

\section{Tyrimo rezultatai}

I tipo MI buvo diagnozuotas 1467 pacientams $(87,95$ \%), II tipo MI - 116 pacientu (6,95 \%). Pacientų amžiaus vidurkis $-66,74 \pm 11,98$ m., $66 \%$ visų tiriamujų buvo vyrai, $34 \%$ - moterys. Pacientams, sergantiems II tipo MI, statistiškai reikšmingai dažniau nei pacientams, sergantiems I

2 lentelè. Tyrime vertinti demografiniai duomenys ir laboratoriniai rodikliai

\begin{tabular}{|l|l|l|l|}
\hline Rodiklis & $\begin{array}{l}\text { II tipo MI } \\
(\mathbf{n}=\mathbf{1 1 6})\end{array}$ & $\begin{array}{l}\text { I tipo MI } \\
(\mathbf{n}=\mathbf{1 4 6 7})\end{array}$ & $\begin{array}{l}\mathbf{p} \\
\text { reikšmė }\end{array}$ \\
\hline Amžius & $\mathbf{6 7 , 5 6} \pm \mathbf{1 3 , 0}$ & $\mathbf{6 6 , 6 8} \pm \mathbf{1 1 , 9}$ & $\mathbf{p}=\mathbf{0 , 5 4 6}$ \\
\hline Moterys & $\mathbf{3 9} \%$ & $\mathbf{3 4} \%$ & \multirow{2}{*}{$=\mathbf{0 , 3 8 8}$} \\
\hline Vyrai & $\mathbf{6 1} \%$ & $\mathbf{6 6} \%$ & \\
\hline Troponinas & $\mathbf{8 , 9 5} \pm \mathbf{1 8 , 8}$ & $\mathbf{2 2 , 8 3} \pm \mathbf{7 0 , 0}$ & $\mathbf{p}<\mathbf{0 , 0 0 1}$ \\
\hline Kreatininas & $\mathbf{1 2 2 , 5 3} \pm \mathbf{1 2 6 , 6}$ & $\mathbf{1 0 4 , 7 5} \pm \mathbf{1 4 2 , 9}$ & $\mathbf{p}=\mathbf{0 , 3 2 9}$ \\
\hline BNP & $\mathbf{1 3 4 6 , 3 9} \pm \mathbf{1 7 1 4 , 4}$ & $\mathbf{9 5 9 , 1 7} \pm \mathbf{2 4 4 5 , 6}$ & $\mathbf{p}=\mathbf{0 , 2 8 3}$ \\
\hline
\end{tabular}

tipo MI buvo diagnozuojama anemija (65 \% ir $27 \%$ atitinkamai, $\mathrm{p}<0,001$ ), dažniau stebèta tachikardija (38 \% ir $9 \%$, $\mathrm{p}<0,001)$, dažnesnis naujai atsiradęs prieširdžių virpejjimas $(13 \%$ ir $4 \%, p=0,001)$ ir dažniau nustatomas reikšmingai sumažejęs funkcinis pajègumas ( $<100$ metrų) (44 \% ir 19\%, $\mathrm{p}=0,008)$. Pacientams su II tipo MI dažniau buvo stebèta mažesnè troponino koncentracija $(8,95 \pm 18,8$, I tipo MI - 22,83 $\pm 70,0, p<0,001)$. Kiti vertinti rodikliai pateikiami 2 lentelëje.

$87 \%$ pacientuc su II tipo MI ir $96 \%$ su I tipo MI buvo atlikta koronarografija $(\mathrm{p}=0,002)$. Kelių vainikinių arterijų pažeidimas buvo rastas $49 \%$ pacientų su I tipo MI ir $28 \%$ pacientų su II tipo MI. Perkutaninè koronarinè intervencija atlikta $42 \%$ pacientų, sergančių II tipo MI ir $82 \%$ sergančių I tipo MI. Gydymas antiagregantais rečiau skirtas pacientams su II tipo MI (54 \%, I tipo MI - $76 \%$, p <0,001). Be to, pacientams su II tipo MI stebètos dažnesnès mirtys ligoninèje (II tipo MI - $10 \%$, I tipo MI $-4 \%$, p=0,049). Komplikaciju išsivystymo dažnis tarp grupių nesiskyrè.

\section{Aptarimas}

Mūsų atliktas tyrimas parodè, kad II tipo MI diagnozuojamas kur kas rečiau, nei I tipo MI. Pacientams su II tipo MI taip pat kaip ir pacientams su I tipo MI randamas ir gydomas vainikinių arterijų pažeidimas, tačiau pacientams su II tipo MI jis yra kur kas retesnis ir tik greta pagrindinès MI priežasties esantis radinys.

Švedijos registro, ị kurị ịtraukti 20138 pacientai, duomenimis, II tipo MI diagnozuotas 7,1 \% pacientų. Skirtingų miestų II tipo MI dažnis registre varijavo nuo $0,2 \%$ iki $13 \%$, o tai parodo diagnostikos problematiškumą [8]. Saaby L. ir kt. [9] Danijoje atliktame tyrime II tipo MI

3 lentelè. I ir II tipo miokardo infarkto skirtumai

EKG-elektrokardiograma, MI-miokardo infarktas, konc. - koncentracija.

\begin{tabular}{|l|l|}
\hline I tipo miokardo infarktas & II tipo miokardo infarktas \\
\hline Dažniausiai spontaninis ir & Susijęs su miokardo deguonies \\
susijęs su ST segmento po- & poreikị didinančiomis būklëmis \\
kyčiais EKG. & (pvz., tachikardija) arba sutri- \\
Nėra būklių didinančių mio- & kusiu deguonies tiekimu (pvz., \\
kardo deguonies poreikị ar & hipotenzija dèl nukraujavimo). \\
mažinančių miokardo krau- & Rečiau jaučiamas tipinis krūti- \\
jotaką. & nės skausmas. \\
Dažnai jaučiamas tipinis krū- & EKG pokyčiai dažnai minima- \\
tinès skausmas. & lūs ir nespecifiniai. \\
Ženklus troponino konc. pa- & Troponino konc. padidejjimas \\
didėjimas. & nežymus. \\
Koronarografijos metu daž- & Koronarografijos metu daž- \\
niausiai stebimas dèl ateros- & niausiai nestebima vainikinès \\
klerozinès plokštelès ply- & arterijos okliuzija. \\
šymo susiformavęs trombas & \\
vainikinėse arterijose. & \\
\hline
\end{tabular}


dažnis siekè 24,8 \%. Švedijos ir Danijos studijose, kaip ir mūsų tyrime, pacientams su II tipo MI rečiau buvo atliekama perkutaninè koronarinè intervencija, rečiau skirtas tinkamas medikamentinis gydymas, stebètas mažesnis troponino koncentracijos padidejimas. Danijoje atlikto tyrimo duomenimis, II tipo MI dažniau diagnozuojamas moterims, vyresnio amžiaus pacientams, turintiems daugiau šalutinių ligų. Alpert JS. Ir kt. [6] apibendrindami studijų, analizavusių I ir II tipo MI skirtumus, išskyrè pagrindinius šiuos MI tipus skiriančius bruožus (3 lentelè).

Stein GY. ir kt. [10] atlikto tyrimo duomenimis, $50 \%$ II tipo MI ịvyksta dèl anemijos ir sepsio. Pacientai su II tipo MI dažnai turi didelę širdies ir kraujagyslių ligų riziką, todèl intervencinis gydymas gali būti taikomas tam tikrai daliai pacientų. Tačiau dažniausiai šiems pacientams pirmiausia reikalingas MI sukèlusios būklès stabilizavimas ir medikamentinis gydymas. Mūsų atlikto ir šio tyrimo rezultatai sutampa - pacientai, sergantys II tipo MI, rečiau gauna tinkamą medikamentini gydymą, nei sergantys I tipo MI. Be to, Stein GY. ir kt. tyrime pacientai buvo sekami vienerius metus ir II tipo pacientų mirtingumas buvo didesnis. Taigi, siekiant mažinti II tipo MI sergančių pacientų mirštamumą, svarbu laiku diagnozuoti ir tinkamai gydyti II tipo MI.

\section{Išvados}

1. II tipo miokardo infarktas diagnozuotas beveik 12 kartų rečiau negu I tipo miokardo infarktas.

2. Pacientų, sergančių II tipo miokardo infarktu, didesnis hospitalinis mirštamumas.

3. II tipo miokardo infarktu sergantiems pacientams dažniau diagnozuota anemija, tachikardija, naujai atsiradęs prieširdžių virpèjimas, mažesnis funkcinis pajègumas ir mažesnè troponino koncentracija.

4. Pacientams su II tipo miokardo infarktu rečiau taikytas intervencinis gydymas ir gydymas antiagregantais.

\section{Literatūra}

1. Lippi G, Sanchis-Gomar F, Cervellin G. Chest pain, dyspnea and other symptoms in patients with type 1 and 2 myocardial infarction. A literature review. Int J Cardiol 2016;215:20-2.

https://doi.org/10.1016/j.ijcard.2016.04.045

2. Lettieri C, Zavalloni D, Rossini R. et al. Management and longterm prognosis of spontaneous coronary artery dissection. Am J Cardiol 2015;116:66-73.

https://doi.org/10.1016/j.amjcard.2015.03.039

3. Thygesen K, Alpert JS, White HD. Joint ESC/ACCF/AHA/ WHF task force for the redefinition of myocardial infarction. Universal definition of myocardial infarction. J Am Coll Cardiol 2007;50:2173-2195.

https://doi.org/10.1016/j.jacc.2007.09.011
4. Thygesen K, Alpert JS, White HD. Joint ESC/ACCF/AHA/ WHF task force for the redefinition of myocardial infarction. Universal definition of myocardial infarction. Eur Heart $\mathbf{J}$ 2007;28(20):2525-2538. https://doi.org/10.1093/eurheartj/ehm355

5. Thygesen K, Alpert JS, White HD. Joint ESC/ACCF/AHA/ WHF task force for the redefinition of myocardial infarction et al. Universal definition of myocardial infarction. Circulation 2007;116(22):2634-2653.

https://doi.org/10.1161/CIRCULATIONAHA.107.187397

6. Alpert JS, Thygesen K, Antman E, Bassand JP. Myocardial infarction redefined - a consensus document of The Joint European Society of Cardiology/American College of Cardiology Committee for the redefinition of myocardial infarction. J Am Coll Cardiol 2000;36(3): 959-969. https://doi.org/10.1016/S0735-1097(00)00804-4

7. Thygesen K, Alpert JS, White HD. et al. Third universal definition of myocardial infarction. Eur Heart J 2012;33:2551-2567. https://doi.org/10.1093/eurheartj/ehs184

8. Baron T, Hambraeus K, Sundstrom J. et al. Type 2 myocardial infarction in clinical practice. Heart 2015;101:101-6.

https://doi.org/10.1136/heartjnl-2014-306093

9. Saaby L, Poulsen TS, Diederichsen AC. et al. Mortality rate in type 2 myocardial infarction: observations from an unselected hospital cohort. Am J Med 2014;127:295-302.

https://doi.org/10.1016/j.amjmed.2013.12.020

10. Stein GY, Herscovici G, Korenfeld R. et al. Type-II myocardial infarction--patient characteristics, management and outcomes. PLoS One 2014;9(1):e84285.

https://doi.org/10.1371/journal.pone.0084285

TYPE 2 MYOCARDIAL INFARCTION

P. Šerpytis, S. Glaveckaitė, E. Butkutė, A. Jucevičienė, R. Šerpytis

Key words: type 2 myocardial infarction, myocardial infarction, clasification of myocardial infarction.

Summary

Myocardial infarction is the leading cause of death in many countries around the world. The use of troponin in clinical practice as ,gold standard" improved diagnostic of myocardial infarction without coronary artery occlusion. In 2007, the Task Force for the Universal Definition of Myocardial Infarction published an international consensus document, where 5 myocardial infarction subtypes were defined. Type II myocardial infarction brought confusion in clinical practice. There are the lack of data about differences between type I and II myocardial infarction frequency, symptoms and clinical outcomes. The aims of our study were to evaluate the clinical onset, course, treatment and outcome differences between patients with type I and II myocardial infarction.

Study methods: Retrospective study was conducted to analyze data of 1583 patients with MI diagnosis registered in the database of Acute coronary syndromes monitoring system during the year 
2011-2015 in Vilnius University clinics Santaros. Patients with type I and II myocardial infarction were analyzed. Demographic parameters, laboratory tests, interventional and medical treatment and disease outcomes were examined.

Study results: Type I myocardial infarction was diagnosed for 1467 patients $(87.95 \%)$, type II - 116 patients (6.95\%). Comparing groups of patients with type II and I myocardial infarction significant differences were found between the number of patients with anemia, tachycardia, new onset atrial fibrillation and significantly $(<100 \mathrm{~m}$.) impaired functional capacity - all parameters were worse in patients with type II myocardial infarction. Group of patients with type II myocardial infarction also had lower troponin concentration, lower number of damaged coronary arteries and a lower degree of stenosis. Coronarography, percutaneous coronary intervention and antiplatelet treatment $(54 \%$ vs. $76 \%$; $<<0.001)$ were applied less often for these patients. Group of patients with type II MI stood out with higher hospital mortality ( $10 \%$ vs. $4 \%$; $\mathrm{p}=0.049)$.

Conclusions: Type II MI is diagnosed almost 12 times less frequent than type I MI, however patients with type II MI have higher hospital mortality. Type II MI patients are more frequently diagnosed with anemia, tachycardia, new onset atrial fibrillation, significantly impaired functional capacity and lower troponin concentration than those with type I MI. Interventional and antiplatelet treatment is applied less often in type II MI patients.

Correspondence to: ebutkute@gmail.com

Gauta 2017-05-24 